\title{
FRONTERAS LEGALES Y LABORALES: DELINCUENTES URBANOS, EXPERIENCIAS CARCELARIAS Y ORDEN POLICIAL EN HIJO DE LADRÓN
}

\author{
Lorena Ubilla Espinoza ${ }^{1}$ \\ Universidad Diego Portales \\ Santiago, Chile \\ lorena.ubilla@mail.udp.cl
}

\begin{abstract}
RESUMEN / ABSTRACT
Una de las consecuencias del proceso de modernización del primer cuarto del siglo XX fue el fortalecimiento de los medios de represión al delito. Bajo el lema de combatir la delincuencia, una serie de medidas sirvieron también para reprimir a quienes no respondían a la ética del trabajo ni al comportamiento político que esperaban las clases dirigentes y sus medios periodísticos afines. Este artículo plantea que un análisis histórico de Hijo de ladrón, novela icónica de Manuel Rojas, permite acceder a las representaciones del delincuente y a la experiencia carcelaria de los pobres de la ciudad en el contexto de la ofensiva modernizante del aparato estatal.
\end{abstract}

Palabras clave: Manuel Rojas, Hijo de ladrón, delincuencia, modernización estatal, cuestión social, Chile.

LEGAL AND LABOR BORDERS: URBAN FELONS,

\section{IMPRISONMENT EXPERIENCES AND POLICE ORDER IN HIJO DE LADRÓN}

One of the consequences of the modernization process occurred during the first quarter of the 20th Century was the strengthening of the means used for the repression of crime. Under the slogan of fighting crime, a series of measures were also taken to repress those who did not respond to the work ethics or the political behavior expected by the ruling class and the

1 Candidata a Doctora en Historia por la Universidad de Santiago de Chile. 
media they would control. This article proposes that by conducting a historical analysis of Hijo de ladrón, Manuel Rojas'iconic novel, we can have access to the representations of the criminal as well as the prison experience lived by the poor in the city, within the context of the modernizing offensive launched by the state apparatus.

KEYWORDS: Manuel Rojas, Hijo de ladrón, delinquency, state modernization, social question, Chile.

Recepción: 05/01/2021

Aprobación: 27/01/2021

\section{INTRODUCCIÓN}

Para quienes nos interesamos en la historia de las clases populares urbanas, la literatura social emerge como un registro de indudable riqueza. Lejos de buscar en ella la concordancia de personajes y hechos históricos, y más lejos aún de comprenderla como un reflejo de su tiempo, la lectura de Hijo de ladrón que propongo se interna en dos claves interpretativas insertas en el contexto de la cuestión política y social de inicios del siglo XX. Por una parte, la preocupación que diversos medios oficiales expresaron frente al aumento en las cifras de criminalidad, asociándolas a un mundo popular diverso en el que convivieron desde delincuentes a trabajadores movilizados. Y por otra, la configuración de un engranaje jurídico-estatal orientado a erradicar una serie de prácticas cotidianas mediante ordenanzas que limitaron la autonomía laboral y la circulación callejera.

Este análisis histórico de la novela explora las "estructuras de sentimiento" de los pobres urbanos, personas hacia quienes se dirigió mayoritariamente la arquitectura estatal y el orden policial. Con dicha categoría me refiero a las experiencias compartidas por un grupo social dentro de una cultura dominante, y a los significados, valores y expresiones que dan cuenta "del pensamiento tal como es sentido y el sentimiento tal como es pensado". Este conjunto de experiencias históricas se enmarca en las interacciones entre clases, y tiene la capacidad de producir una cultura distintiva que se manifiesta en las prácticas sociales, entendidas de modo inseparable de la estructura material (Williams 169-170).

Problematizando las contradicciones del proyecto moderno y las posibilidades de construir un discurso alternativo de liberación humana y transformación social, planteo que Hijo de ladrón expresa una sensibilidad crítica hacia los mecanismos punitivos y las arbitrariedades de la justicia, subvirtiendo los códigos representacionales de la relación entre delincuente 
y transgresión. De igual modo, sostengo que la experiencia carcelaria fue una realidad cercana a las clases populares, ya fuese por la efectiva comisión de delitos, por la serie de disposiciones que normaron su presencia en la ciudad o por la criminalización de la protesta obrera y sus repertorios de acción. A diferencia de la visión extendida por parte de las clases dirigentes respecto a que la delincuencia era producto de la degeneración, la dimensión éticopolítica de la narrativa rojiana permite comprender que cualquier hombre y mujer popular podía transformarse en un potencial desestabilizador del orden social-moral y en un huésped ocasional o permanente del presidio estatal.

\section{DE LA PREOCUPACIÓN OFICIAL A LAS TRAYECTORIAS DELICTUALES}

A inicios del 1900 la rápida migración acompañó el debate sobre las diversas problemáticas sociales, urbanísticas e incluso estéticas, que traerían los nuevos habitantes que venían a instalarse a la ciudad y que ponían en entredicho la frontera de relaciones entre lo público y privado.

Tesis universitarias, revistas especializadas e informes estadísticos sobre la criminalidad proliferaron a la par de la modernización judicial y policial, revelando una creciente proporción de la población penal que se mantuvo sobre el incremento demográfico nacional. Después de 1902, año en que comenzó a regir la Ley de Alcoholes, la cantidad de personas que ingresaron a los recintos carcelarios rara vez bajó de las cincuenta mil, aumento significativo si consideramos que entre 1894 y 1901 el promedio alcanzó a los treinta y cinco mil individuos (Palma, Ladrones 130-131).

Los medios de comunicación se hicieron partícipes de esta sensación de inseguridad demandando reformas legislativas y la apertura de instituciones destinadas al encierro y regeneración de quienes delinquían o mostraban "signos" que los acercaban a este mundo. De ese modo, el tono epocal que se percibe a partir de diversas fuentes evidencia que la ansiedad frente al aumento delincuencial fue una preocupación que excedió los círculos oficiales y que sobrepasó, con mucho, el interés académico de juristas y criminólogos.

La carencia de un trabajo formal, la ausencia de disciplina, la falta de higiene, la mala instrucción, la afición al alcohol y la reincidencia en actos delictuales fueron los indicadores que las clases dirigentes identificaron como los nutrientes de un bajo fondo en continua expansión y causas de 
la conformación de un estrato de delincuentes profesionales. No sólo su número iba en constante aumento, decían los reportajes periodísticos, además su actuar era diferente -casi científico, agregaría el Boletín de la Policía de Santiago- al del tradicional bandido rural. En el editorial de 1902, la publicación policial aludía a quienes utilizaban los modernos medios de transporte y empleaban conocimientos químicos para falsificar billetes, alimentos y bebidas alcohólicas. "Cada progreso científico que facilita la vida en la ciudad", concluía el medio institucional, "va seguido de una nueva forma de delito" (Boletín de la Policía de Santiago 452-454)². Así, la relación entre actos delictuales y modernidad emergía como uno de los efectos colaterales de la vida metropolitana, convirtiendo a este espacio en un lugar propicio para simular la identidad y favorecer el contacto entre extraños.

Ladrones especializados y unidos por una trama de relaciones ilícitas abundaron en diversos registros, reforzando el argumento de la "mala vida" de las clases trabajadoras ${ }^{3}$. Distante a esta visión, aunque para nada lejos del panorama histórico descrito, Hijo de ladrón permite ajustar el lente al internarse en las trayectorias biográficas de este nuevo tipo de delincuente, presentándolas como social y culturalmente situadas, y cuestionando con esta operación los discursos de defensa social, del determinismo y de la degeneración ambiental, premisas en boga desde fines del siglo XIX en círculos de especialistas y difundidas ampliamente por la prensa burguesa ${ }^{4}$.

2 El Boletín de la Policía de Santiago (1901-1924) expresa el discurso modernizador de la Prefectura y la interacción policial con la Intendencia, el municipio y la comunidad. Al respecto, véase Palma ("El Boletín de la Policía de Santiago. Autorretrato de una policía urbana (1901-1924)").

En el cambio del siglo XIX al XX, surgió en Italia el concepto de mala vita. Exportado a España y desde ahí a Latinoamérica, concitó un interés importante en la producción argentina de Eusebio Gómez y José Ingenieros. Su éxito respondió a la preocupación por las nuevas formas de delincuencia en un momento en que el crecimiento de las ciudades era exponencial y la vida de los inmigrantes inquietaba por su dificultad para aprehenderla y controlarla. A partir de un juego de oposiciones binarias entre valores y conductas consideradas sanas, limpias y honestas, y las definidas como inmorales, subversivas y peligrosas, se incluyó una amplia gama de individuos y grupos marginales caracterizados por las clases dirigentes como faltos de disciplina interior y exterior. Conjugando las premisas de la degeneración social, se consideró bajo esta denominación a los habitantes de los suburbios y barrios pobres, quienes desarrollaban un estilo de vida próximo a la criminalidad o abiertamente delincuencial. Al respecto, véase Zaffaroni.

Tanto la narrativa social como los relatos testimoniales de presos contribuyeron, con fuerza desde la segunda mitad del siglo XX, a cuestionar la asociación entre pobreza y 
Introducirnos en la primera parte de la novela nos lleva a los recuerdos de un pasado infantil lejano en el que se intercalan una serie de actuares delictuales que Aniceto conoce en voz de los mismos presos. Su acercamiento al mundo del delito comienza al enterarse de la ocupación del padre, "El Gallego", famoso ladrón nocturno de joyas que abría cerraduras de casas con refinada precisión. Para la policía, un "monrero"; para el círculo familiar y los compañeros de oficio, un hábil, sofisticado e incluso elegante trabajador: "Mi padre desaparecía por cortas o largas temporadas; viajaba, se escondía o yacía en algún calabozo; reaparecía, a veces con unas hermosas barbas, siempre industrioso, trabajando sus moldes de cera, sus llaves, sus cerraduras" (Rojas 386).

Las historias se suceden luego en una trama que explora los azares y dificultades de otros ladrones. En la primera detención de Aniceto a sus doce años -o la primera "cuota" que ilustra el paso de la infancia a la adolescencia ${ }^{5}$ - comparte su celda con “L.C.", ladrón conocido que comenzó a robar desde niño disimulando sus fechorías con un cajón de lustrabotas ${ }^{6}$. A partir de él nos enteramos de Victoriano Ruiz, un agente de policía ejemplar quien, tras años de perseguir "carteristas" en la estación de ferrocarriles, se alía con estos para recibir parte del botín extraído a los pasajeros; también del Negro Antonio, "fanfarrón y estúpido" delator de Ruiz (Rojas 406); del Manco Arturo, falto de brazo y pierna producto de una persecución policial; y del Camisero, ladrón español y viajero, célebre por su gracia y simpatía.

criminalidad y los estereotipos del delincuente como un ser anormal. Tal como plantea Marco Antonio León, aunque no se puede afirmar tajantemente que los prejuicios hayan terminado, es claro que en estos años la literatura contribuyó a entregar percepciones más variadas sobre los sujetos criminales, además de evidenciar que la transgresión a la legalidad vigente debía entenderse como un acto posible en todo ser humano, y no determinado siempre por la herencia o el medio social (167-168).

Siguiendo a Federico Schopf en el prólogo de Páginas excluidas, las "cuotas" son las experiencias previas del narrador actual que "fragilizan, desequilibran la vida ordenada y protegida de Aniceto en el seno de su familia". Estos cuatro momentos corresponden a su primera detención policial de niño, a la muerte de su madre, al encarcelamiento del padre y a su propia prisión, tras ser injustamente acusado del asalto a una joyería (35-36).

La historiadora argentina Lila Caimari plantea que la categoría policial "ladrones conocidos", sintetizada como "LC", designaba a fines del siglo XIX a los delincuentes bonaerenses que tenían en su prontuario más de dos delitos contra la propiedad (La ciudady el crimen 53). 
En los relatos de estos "maleteros" tranviarios se conjuga la especialización y la reincidencia, ambos fenómenos que llamaron la atención de sus contemporáneos en tanto se trataba de personas que hicieron del robo contra la propiedad su opción laboral. Legitimados entre sus pares por su prontuario y habituados a tratar con agentes y jueces, fueron una de las caras más visibles de los miedos citadinos por representar la configuración -imaginaria o realde un submundo que operaba con lógicas propias y que desafiaba el poder y la tranquilidad de las autoridades. En ese sentido, la novela nos acerca a una nueva cartografía del robo marcada por los procesos modernizadores y la expansión demográfica. La estación de trenes aparece como una especie de ser vivo, un lugar físico y simbólico en el que se mezcla el honor y la reputación delictual con la labor policial y la resistencia a ella, un espacio que a Rojas le permite plantear que los delitos fueron producto tanto de los cambios en la estructura económica como el resultado de actitudes culturales que se desarrollaron a la par de las diferencias de clase y criminalidad.

Tranvías y trenes, símbolos del transporte moderno, cobijaron a las distintas clases sociales en un viaje diferenciado por la capacidad de pago. Esta convivencia interclasista llevó a algunos medios impresos, como la revista Sucesos ${ }^{7}$, a publicar foto-reportajes para dar a conocer los rostros y modus operandi de los nuevos delincuentes. En la crónica "Los maleteros en los tranvías", la publicación alertaba a sus lectores de una clase de sujetos que el argot policial designaba bajo el nombre de "pungas". En ella aparecía "una media docena de conocidos ejemplares santiaguinos" identificados todos por sus apodos, como Ernesto Núñez Carmona, alias "El Cojo Machette", distinguido en el "gremio como uno de los más atrevidos y audaces", y Manuel Riquelme Quezada, "El Chino", "gran especialista en el hurto de carteras" y famoso por habérsela sustraído a un ministro de Estado (Sucesos 17 de septiembre de 1914). Un año más tarde, en la autodenominada "campaña moralizadora", los retratos de dieciséis criminales sorprendidos in fraganti volvían a escena sindicados como "infelices enfermos, catalogados por algunos criminalistas entre los semi-locos”. En un ejercicio de caracterización que

\footnotetext{
La revista Sucesos (1902-1932) fue expresiva del desarrollo de un mercado cultural que vehiculizó la experiencia cotidiana de la modernidad. Inscrita en el género magazine, destacó por la variedad de sus temáticas, la diversidad de lenguajes y estilos, la divulgación y vulgarización del conocimiento científico y la incorporación de ilustraciones y registros fotográficos. Al respecto, véase Ossandón y Santa Cruz.
} 
involucró también a los agentes del Estado, los reporteros informaron de los sobrenombres, las especialidades y los nuevos lugares del delito, sometiendo a los ladrones a una especie de linchamiento simbólico. La misma crónica, evocando épocas pasadas, sentenciaba: "Hoy las costumbres han variado [...] no se ata al delincuente a la vía pública con un cartel que pregone su infamia". En ausencia de ello "se tiene la publicidad de diarios y revistas que lo señalan a sus lectores para que lo sancionen con su desprecio" (Sucesos 23 de diciembre de 1915).

Desconocemos si Manuel Rojas tuvo a la mano estos informes noticiosos, aunque es probable que así fuese. Lo que sí sabemos es que, en Hijo de ladrón, la aparición de "El Gallego" en un medio de comunicación es el motivo que obliga a la familia a cambiar de casa y ciudad y a terminar la relación literaria que Aniceto forja con la arrendataria: "Un día, en el diario que ella acostumbraba a leer, apareció, entre otras, una fotografía de mi padre. Era él, sin duda ni disimulo posible, y el diario lo señalaba como ladrón peligroso, dando su nombre, su apodo y todos sus antecedentes policiales" (Rojas 587).

Sin embargo, poco tenía "El Gallego" del delincuente profesional que en 1906 el Boletín de la Policía de Santiago asimiló a la "peste y plaga" más peligrosa de la sociedad. Si contrastamos su descripción literaria veremos que escasamente se asemeja a aquellos "[s]eres abyectos y despreciables [...] bestias peligrosas, a quienes la pereza, el amor de los goces y los vicios, lanzan a buscar hasta en el crimen, los medios de poder satisfacer sus pasiones malsanas" (Boletín de la Policía de Santiago 379-380). Por el contrario, el padre era recordado como "sobrio, tranquilo, económico y muy serio en sus asuntos". Más aún: "de no haber sido ladrón habría podido ser elegido, entre muchos, como el tipo de trabajador con que sueñan los burgueses y marxistas de todo el mundo" (Rojas 387).

En esta operación se aprecia una diferencia radical. Si las clases dirigentes, amparadas en el higienismo y en la criminología positivista construyeron una identidad colectiva e individual sobre el delincuente que apelaba a su degeneración, en Hijo de ladrón vemos a seres humanos que cometieron delitos, ya fuera por las deficiencias de la estructura laboral, porque las circunstancias los obligaron a ello, porque no contaban con un ingreso estable o, simplemente, porque decidieron infringir las normas y vivir del robo. En esta mirada desde abajo, los ladrones formaron parte de una vida cotidiana tejida en espacios habitacionales y de sociabilidad y cuyos actos, si bien merecieron sanción, en ningún caso llegaron a comprenderse como 
una amenaza al cuerpo social ${ }^{8}$. Precisamente por ello, los personajes generan empatía, porque hay un sustrato de humanidad que históricamente les fue negada por su condición de marginalidad. Aunque Aniceto no pensara en dedicarse a este oficio, sí consideraba que se trataba de personas con las mismas cualidades: "para mí regían las mismas leyes, y el hecho de que fuesen hijos de gente honrada [refiriéndose a sus compañeros de escuela] no les daba, ni en el presente ni el futuro, ninguna ventaja, así como yo tampoco la tenía por el hecho de ser hijo de ladrón" (Rojas 522).

El detalle con el que se describen en la novela los "escapeos" y "monras", además de las sofisticadas puestas en escena para estafar", hablan de un actuar refinado y astuto, de ladrones de guante blanco que escogieron atajos para disfrutar de una vida que sólo le estaba reservada a la burguesía. Y esto era posible tanto por la circulación de una cultura judicial expresada en el conocimiento de saberes y procedimientos legales, como por las redes de protección, complicidad y solidaridad delictual que incluso traspasaron la frontera nacional. Es decir, una serie de relaciones sociales que requerían de condiciones estratégicas para su efectividad y el resguardo de sus integrantes. Sin ellas, es probable que el robo hubiese sido una actividad menos habitual, de altos costos objetivos y pocos beneficios subjetivos. De hecho, cuando la familia acoge a Alfredo, Aniceto reflexiona al respecto:

\footnotetext{
El conventillo, espacio habitacional de las clases populares a inicios del siglo $\mathrm{XX}$, aparece en numerosas ocasiones retratado en la novela. Este lugar, una especie de ente autónomo en la resolución de las dificultades de vida de los pobres, albergó a una diversidad de sujetos, convirtiéndolo en la expresión manifiesta de las desigualdades modernas. Como expresa Rojas, en esta pequeña ciudad marginal convivió lo público con lo privado, la salud con la enfermedad, la vida con la muerte, la higiene con la insalubridad, la oficialidad laboral con la marginalidad y la politización con el más profundo desinterés: "en los conventillos se acostumbra uno a vivir al lado de la gente más extraordinaria: ladrones, policías, trabajadores, mendigos, asaltantes, comerciantes, de todo; gente que se cambia de un lugar a otro con más frecuencia que de ropa interior; pero en alguna parte han de vivir, ¿no es cierto?” (568).

El vagabundo de las tortugas, alter ego de Máximo Jeria, es quien relata a Aniceto las estafas de dos de sus compañeros de andanza. Simulando identidades y apelando a sus capacidades retóricas, le explica una de las variantes del llamado "cuento del tío": "Se dedicaron al comercio de joyas, de joyas baratas, por supuesto [...] joyas que cualquiera podía comprar [...] a precios bajísimos, pero que, ofrecidas por ellos con el arte con que lo hacían, alcanzaban precios bastante por encima del verdadero [...] La treta era muy sencilla y yo mismo colaboré en dos o tres ocasiones, asombrado de lo fácil que resultaba comerciar; sólo se necesitaban resolución y dominio de sí mismo" (Rojas 491).
} 
Ignoro si en lejanas ciudades, en aquellas ciudades o lugares que mi padre visitaba durante sus viajes, existían seres que, como nosotros, como mis padres, mejor dicho, estuviesen dispuestos a recibirle y le recibieran cuando él, alguna vez, estuvo enfermo o le atendieran cuando caía bajo las manos de algún policía. Tal vez sí; ojalá que sí (Rojas 539).

Las modalidades y el funcionamiento de estas redes fueron variadas, aunque aludiré aquí a tres modalidades. De partida, el apoyo económico tras la detención de algún compañero de andanzas. Nicolás, amigo de "El Gallego", cuya limpieza, suavidad y desprendimiento lo convirtieron en una especie de arcángel familiar, es quien mejor ilustra los modos de cumplir con esta recíproca función:

"Me llamo Nicolás [...] soy amigo de su marido y he sido alguna vez su compañero. Saldrá pronto en libertad; no se aflija”, y se fue, y dejó sobre la mesa un paquetito de billetes de banco, limpios, sin una arruga $[\ldots]$ Mi madre quedó deslumbrada por aquel individuo [...]; por eso, cuando mi padre, varios años después, le comunicó que Nicolás necesitaba de su ayuda, ella, con una voz que indicaba que iría a cualquier parte, preguntó: “¿Dónde está?” [...] En la Penitenciaría. ¿Te acuerdas de aquellos billetitos que regalaba en Brasil? Veinticinco años a Ushuaia (Rojas 385).

La red se extendía luego a quienes vivían de la reducción de especies, como Isaías, antiguo ladrón nocturno quien, tras perder su pierna por cruzar borracho un paso de trenes, "se dedicaba a comprar pequeños robos que vendía a clientes tan miserables como él" (Rojas 431); o de la provisión de datos, como el "inocente y tímido" Pedro El Mulato que no había robado en su vida, pero "sabía más que toda la policía y el gremio de ladrones juntos. Sufrió algunas condenas por encubridor, pero la cárcel no hizo más que agudizar su admiración y su amor por los ladrones" (Rojas 529).

Por último, destacan las redes transnacionales configuradas a partir de los frecuentes cambios de país y ciudad. Aunque el viaje no era condición necesaria del modus operandi, se convertía con frecuencia en una consecuencia inevitable derivada de la necesidad de huir y llevar el oficio a nuevas partes. Como señalé, en la profesionalización del delito los ladrones no sólo usaron sistemáticamente las innovaciones tecnológicas de la modernidad, también se caracterizaron por prácticas de movilidad territorial facilitadas por los medios de transporte. Tanto preocupaba el delincuente viajero, sobre todo 
aquel que utilizaba las rutas del Atlántico y que entraba por Valparaíso a tierras chilenas, que en 1905 se inauguró la Conferencia Internacional de Policía en Buenos Aires con el objeto de tratar esta problemática e intercambiar fichas y fotografías, muchas de ellas de anarquistas "indeseados" (Galeano 152) ${ }^{10}$.

En la novela vemos que este actuar transnacional se ejemplifica en "El Gallego", en el cubano "Víctor Rey" y en "El Camisero" español-seudónimos que marcan una diferencia considerable con el ratero común-, quienes se desplazan constantemente, estudiando y nutriéndose de información. Y en ello Pedro El Mulato resultaba esencial:

En ocasiones el ladrón fallaba el golpe y debía huir o caía preso; en cualquier caso informaba a Pedro de los obstáculos hallados y de lo que, a su juicio, era necesario hacer para salvarlos. Muchas veces un asunto en que fracasaban unos y otros o que nadie se atrevía a afrontar, cobraba interés internacional: se sabía en Madrid, por ejemplo, o en Valparaíso, en La Habana o en Marsella, que en Río de Janeiro había tal o cual negocio y ocurría que algunos bribones, que vivían a miles de kilómetros de distancia, se entusiasmaban con el asunto y venían a tentar el golpe; acertaban y escapaban o fracasaban y caían. Mi padre acertó en un negocio pequeño y falló en otro grande, y Pedro fue entonces su bastón y su muleta (Rojas 529).

Poco antes de la mencionada conferencia policial, se creó en 1899 la Oficina de Identificación Antropométrica en la Policía de Santiago a partir de los avances que en este campo realizaron sus homólogos en París (método conocido como bertillonage) y Buenos Aires (sistema denominado de impresión dactilar $)^{11}$. Utilizando complementariamente ambos procedimientos,

10 En su estudio sobre la cooperación entre las policías de Santiago, Montevideo, Río de Janeiro y Buenos Aires, Diego Galeano describe los alcances de la resolución sobre "peligrosidad" consensuada en la conferencia de 1905. Los tres primeros acuerdos refirieron a los delitos contra la propiedad o las personas, el cuarto a la trata de blancas, mientras que el quinto y el sexto a los agitadores y subversivos anarquistas.

11 La antropometría fue aceptada por la Prefectura de la policía parisina en 1883 a partir del método propuesto por Alphonse Bertillon, basado en la combinación del registro de medidas corporales, una descripción física estandarizada y la fotografía métrica. Por su parte, en 1895 el policía argentino Juan Vucetich propuso un nuevo sistema de filiación sustentado en la impresión de huellas digitales, bajo el supuesto de su inmutabilidad desde el nacimiento hasta la muerte y de que no había dos individuos en el mundo con la misma combinación. Según Diego Galeano, hacia 1910 eran pocos los países que mantenían el modelo antropométrico 
en las primeras décadas del siglo XX se incrementó la cantidad de sujetos identificados, lo que permitió la construcción de un archivo de identidades y registro de antecedentes. Considerada un arma fundamental en el control de la "peste y plaga" delincuencial, en enero de 1901 el Boletín de la Policía de Santiago publicó el decreto que establecía que todos los jefes de las prisiones capitalinas debían conducir a los reos presuntos y condenados a la Sección de Seguridad para efectuar su filiación antropométrica (229). Leída a la luz de estas iniciativas, la primera detención de Aniceto fue tanto el pago de la "cuota" como el inicio de la marca identitaria policial:

¿Tiene alguna señal particular en el cuerpo? ¿En la cara? Una cicatriz en la ceja derecha; un porrazo, ¿eh?, ojos obscuros; orejas regular tamaño; pelo negro; bueno, se acabó. Seguramente le tocará estar al lado de su padre, no por las impresiones, que son diferentes, sino por el nombre y el apellido. Váyase no más (Rojas 397).

En variados reportajes el boletín de la policía santiaguina instó a que los jueces tuviesen a disposición los registros antropométricos y dactiloscópicos para hacer frente al creciente número de personas condenadas con nombres falsos. Igualmente, y para combatir el uso abusivo del anonimato, alertaba a los guardianes a estar atentos a los cambios fisonómicos y nominales del conjunto de las clases populares, fuesen estos honrados trabajadores, rateros ocasionales o ladrones profesionales. De ahí la preocupación, casi humorística, del agente Prudencio Martínez por consignar el sobrenombre de los arrestados tras el motín de 1914: el nombre, domicilio, oficio o estado civil carecían de importancia para su labor; el apodo, en cambio, proveía de carácter y distinción. Por eso, afirmaba, le gustaban los ladrones:

Ninguno deja de tener apodo. Cada vez que caen presos se cambian nombre y apellido y muchos tienen ya veinte o treinta, pero nunca se cambian el apodo; no pueden, no les pertenece y dejarían de ser ellos mismos. ¿Quién sabe el nombre del Cara de Águila? Nadie, ni su madre, que lo bautizó: todo Chile, sin embargo, conoce su apodo (Rojas 483).

debido al conjunto de mejoras prácticas que implicaban las huellas, a la sencillez y rapidez en su catalogación y a que se necesitaba menos capacitación por parte de los funcionarios policiales (120-141). 
Para finalizar este apartado, cabe señalar que las prácticas delictivas no estuvieron exentas de códigos éticos significativos en el mundo delincuencial-popular. Los delatores, traidores y asesinos fueron merecedores del reproche y de la indiferencia enunciativa del relato. Nada tenían que ver con "El Gallego" ni con sus actividades económicas; eran seres cuya "equivocación o estupidez los hacía peligrosos", seres que vivían siempre a la sombra de ladrones, de caudillos políticos, de dueños de casas de juego y de prostíbulos (Rojas 522). Una diferencia radical separaba a los delincuentes de los rateros. El apodo era una de ellas. La otra, su condición humana. Aquella "palomilla" que la revista Sucesos identificó como "los aprendices de criminales que no tienen siquiera nombre conocido" (13 de febrero de 1908), o que el argot policial denominó como "rateros que roban especies de muy poco valor" (Boletín de la Policía, junio de 1911), fueron también los personajes que Rojas, con distancia afectiva, retrató en el cuento "Canto y baile" o sobre quienes escribió en las crónicas de Páginas excluidas, "Más sobre cuchilleros" y "Variedades del lumpen". Eran ellos los representantes de la clase más baja de la delincuencia; ni ladrones ni asesinos de profesión, "faltándole audacia para lo primero y valor para lo segundo"; eran ellos quienes actuaban "en la obscuridad y en la soledad de las callejuelas apartadas", robando "cuando tienen ocasión de hacerlo" y matando "cuando nadie los ve" (Rojas 210-211).

Para Pablo Piccato la categoría de ratero no fue un invento de los criminólogos sino un producto de las percepciones populares sobre el robo y los ladrones. El término, de uso común en la lengua española, connotaba la bajeza moral relacionada con los sustantivos de 'rata' o 'ratón' y con el adjetivo 'rastrero' (que anda a rastras y, extensivamente, que es vil y despreciable). Por ello, para el historiador mexicano, más que un ser extraño, "el ratero era un sinvergüenza" (228). Si volvemos a Hijo de ladrón, veremos una opinión compartida. El "hombre-cuchillo", los "hombres-rata", o los "hombres de las alcantarillas", salen a escena en la oscuridad del motín y emergen como una masa informe desde los cauces de la ciudad, ese lugar que sirve de morada a "gatos, perros, ratones, pulgas, vagos, maleantes, mendigos, piojos, asesinos" (Rojas 470). Frente a aquellos, que no son parte siquiera del conventillo, que no tienen apodo ni especialización delictual, es el "hombre-mazo" o el obrero consciente quien decide enfrentarlos:

- No soy de la policía, pero tampoco quiero que nos echen la culpa de lo que hacen los sinvergüenzas como tú. Somos trabajadores y no rateros, ¿entiendes? 
Sentí gran admiración por el hombre cuadrado y me acerqué a su grupo [...] el hombre-mazo los conocía y no les temía; más aún, parecía despreciarlos. El hombre-cuchillo no sabía qué diferencia hay entre un trabajador y un ratero y no se inmutó ante el insulto.

[...] El hombre-mazo agregó: - Nunca le han trabajado a nadie y roban a todo el que pueden, a los pobres en los conventillos, y a los borrachos, a las viejas, a los chiquillos; ni siquiera son ladrones; no son más que inmundos rateros (Rojas 467-468).

Este ratero -real o ficticio-, sobre quien se irguió el desprecio y la condena popular, también permite ajustar las interpretaciones oficiales sobre la criminalidad y la identidad delincuencial. A ojos de las clases dirigentes las diferencias no existían; sin embargo, las hubo y fueron significativas. Y no porque el actuar del "hombre-rata" violara la legislación penal sino porque afectaba a la propia comunidad. Aunque los archivos judiciales nos hablen indistintamente de ambos ladrones, el ejercicio narrativo de la novela expresa una sensibilidad crítica hacia esta mirada hegemónica, adentrándose en una especie de imaginario moral configurado a partir de normas compartidas en un espacio tildado como poco civilizado por los promotores de la modernidad. Una de esas tantas experiencias comunes fue la angustia y la frustración, pero también la denuncia hacia los mecanismos punitivos ejercidos sobre el conjunto de los pobres, más allá de si sus ocupaciones traspasaban o no la frontera legal. Estas estructuras expresadas como parte del sentir popular arrojan luces sobre las arbitrariedades cometidas por el orden estatal-policial y permiten someter a discusión las leyes que configuraron el entramado institucional de inicios del siglo XX.

\section{EXPERIENCIAS CARCELARIAS Y ORDEN POLICIAL}

Una serie de saberes expertos, entre ellos la medicina higienista y la criminología positivista, se movilizaron para conocer e internarse en aspectos tan cotidianos como la salud, la alimentación, las condiciones habitacionales, la organización familiar, el uso del tiempo libre y los comportamientos vitales de las clases populares. En ese marco, el delito adquirió visibilidad y se convirtió en un término común para referirse al variopinto de actividades y prácticas de quienes recorrían las calles en busca de un sustento material o que hacían de ella el lugar preferente de la protesta social. En un pasaje que expresa con claridad 
lo dicho, Aniceto reflexiona tras su segunda detención derivada del motín -o la "cuota" que ilustra, esta vez, el paso de la adolescencia a la adultez-: los detenidos eran "obreros, jornaleros, vendedores ambulantes o gente de la bahía [...] Ninguno se veía asustado o apesadumbrado por su situación”. ¿Por qué? Porque es difícil que un hombre del pueblo no haya estado preso alguna o varias veces; "son tantas las causas: desorden, embriaguez, equivocaciones, huelgas, riñas o pequeñas y a veces inocentes complicidades en hechos de poca importancia" (Rojas 479) ${ }^{12}$.

En efecto, tantas podían ser las causas y las menos provenían de quienes se dedicaban profesionalmente al robo. Si volcamos la mirada a inicios del 1900 veremos que la asociación entre pobreza y delincuencia atravesó el espectro político de la época, vinculando en no pocas oportunidades la cuestión social con la criminal y respaldando los antiguos prejuicios raciales y de clase en un vocabulario científico, empírico y racional ${ }^{13}$. Aunque es cierto que se registró un aumento sostenido en las cifras de delincuencia y, dentro de ella, de la profesionalización del delito, no es menos relevante consignar que estos números fueron expresivos tanto de la ampliación de la capacidad de encierro como de la activa intervención policial. La serie de ordenanzas y edictos publicados en el Boletín de la Policía de Santiago denota una densa red de prohibiciones y normas ordenadoras de la presencia del conjunto de los pobres en la ciudad: no implorar la caridad pública, no jugar, no beber, no eludir la jornada laboral, no vagar... Incluso, no cantar, y menos canciones subversivas. El propio Manuel Rojas en Páginas excluidas recuerda:

Estuve dos veces preso y las dos veces una después de la otra: la primera una tarde en que estaba con varios amigos y en un cerro que

12 La detención fue vivida por el propio Rojas en el motín que tuvo lugar en Valparaíso en diciembre de 1914, producto del alza del precio en la tarifa de los tranvías. En Páginas excluidas se refiere a este hecho señalando: "El motín que se describe ocurrió en Valparaíso en 1914 o principios de 1915, no recuerdo exactamente, y lo que ahí le sucede a Aniceto Hevia es exactamente lo que me ocurrió a mí, con la diferencia de que yo no me enfermé: después de doce días de detención fui puesto en libertad" (Rojas 182).

13 Según Luis Alberto Romero, en el transcurso de la década de 1870 la mirada hacia los sectores populares sufre un giro radical al romperse el equilibrio paternalista que había dado forma a la sociedad colonial. La difuminación del "bajo pueblo" aparece asociada a un miedo distinto derivado de la respuesta política organizativa por parte de los trabajadores en el contexto de la cuestión social. De ahí que la elite, urgida por la crisis, se vuelque tanto a la moralización como al control y vigilancia de las instituciones. 
no recuerdo, en la pieza de uno de ellos. No bebíamos ni hacíamos escándalo, sólo cantábamos. De improviso, como mágicamente, aparecieron en la pieza varios policías que, sin dar ninguna clase de explicaciones, nos llevaron a una comisaría (es lo que cuenta uno de los hombres en el capítulo VI de la Segunda Parte [de Hijo de ladrón]). Nos condenaron a cinco días de detención o dos pesos de multa (era la condena que se le daba a los ebrios). Con Francisco Pezoa, el poeta popular autor de la famosa canción titulada "La pampa", cumplimos los cinco días en la Sección de Detenidos (Rojas 196) ${ }^{14}$.

Transformar las identidades de hombres y mujeres populares convirtiéndolos en futuros ciudadanos respetuosos de las normas y en trabajadores útiles a la economía nacional fue el sentido de estas disposiciones, argüidas por los reformadores sociales como el pilar necesario para encaminar al país en la senda del progreso. Y para ello resultaba fundamental internalizar la ética del trabajo, es decir, el precepto fáctico y normativo que permitía a las clases dirigentes contar con una mano de obra permanente. Trabajar-sin importar en la ocupación que fuera, en las condiciones que fueran y con el pago que fuera- fue impuesta como la única forma decente y moralmente aceptable de ganarse la vida y, en ese sentido, también contribuyó activamente a los esfuerzos por reducir las prácticas laborales estacionarias que convivían con el vagabundaje y la mendicidad. De ahí que esta nueva moral convirtiera a los "nómades urbanos" en sujetos de condena, tal como se narra en la novela:

Mis parientes eran seres nómadas [...] errantes de ciudad en ciudad y de república en república [...] individuos [que] se resisten aún, con variada fortuna, a la jornada de ocho horas, a la racionalización en el trabajo y a los reglamentos de tránsito internacional [...] que les permiten conservar su costumbre de vagar por sobre los trescientos sesenta grados de la rosa, peregrinos seres, generalmente despreciados y no pocas veces maldecidos, a quienes el mundo, envidioso de su libertad, va cerrando poco a poco los caminos. Nuestros padres [...] Habrían preferido, como los pájaros emigrantes, permanecer en un mismo lugar hasta que la pollada se valiera por sí misma, pero la

$14 \quad$ El pasaje de Hijo de Ladrón aludido es el siguiente: “- En menos de un mes he caído dos veces preso [...] - ¿Qué le pasó? - ¿Qué no le pasa al pobre? Estaba con unos amigos, tomando unos tragos y cantando en casa de un compadre, cuando se abrió la puerta y entraron varios policías. No estábamos ni borrachos. ¿Qué pasa? Todos detenidos. ¡Bah! ¿Y por qué? Por ebriedad y escándalo" (Rojas 480). 
estrategia económica de la familia por un lado y las instituciones jurídicas por otro, se opusieron a ello (Rojas 383-384).

La ética laboral no solo legitimó la persecución y creó leyes destinadas especialmente a combatir el "creciente número de menesterosos que pululan por la ciudad", además implicó la apropiación del uso del tiempo libre y la condena a los espacios de ocio e improductividad. Como expresaron contemporáneamente las autoridades, la vagancia era la antesala y el preludio de una vida delincuencial. Según señalaba la publicación de los policías capitalinos en abril de 1912, bastaba con mirar el prontuario de los delincuentes habituales para ver en ellos una escala ascendente que comenzaba con la vagancia, seguía con el hurto y terminaba en condenas por "crímenes atroces". El vago, al principio sólo un holgazán y "temible únicamente porque siente necesidades de la vida y no cuenta con los medios de satisfacerlas", se vuelve luego "peligrosísimo" al avanzar en peldaños de perversión moral. Si a esto se agrega la "prédica de las teorías anárquicas, que perturba el criterio de nuestro pueblo, presentando a los ricos como ladrones de los pobres, y al trabajo como invención injusta del capitalista, se habrá hecho de un flojo, posiblemente sólo de un torpe e ignorante, un peligroso enemigo de la colectividad social" (Boletín de la Policía de Santiago 197-198). En esta lectura, la vagancia y holgazanería sumadas a las teorías revolucionarias daban como resultado la anomia social, mal que podía remediarse a través de la ocupación laboral. De ahí que la resistencia al trabajo a la que alude la novela no sea un asunto testimonial, podía implicar efectivamente la detención en comisarías o la reclusión en establecimientos carcelarios.

Entendida esta vez como un escrito filo-anarquista, Hijo de ladrón expresa una multiplicidad de actos cotidianos que se enfrentan con el poder y, más concretamente, con el proceso de proletarización en su variante temporal y en su proyecto de sedentarismo familiar. Destacan aquí los modos de subsistencia alternativa, como pintar por temporadas o recoger metales en la caleta El Membrillo: "por un día de trabajo -dice El Filósofo-, me sale un día de comida, de dormida y de lo demás; miserable, es cierto, como en todos los demás oficios, pero me proporciona lo que necesito" (Rojas 548). O el disfrute de la libertad asociada a una ocupación estacional y a la contraposición de ideales burgueses: "nos reíamos del desnivel; no tenemos mujer ni hijos, no tenemos ropa empeñada $[\ldots]$ es una ventaja $[\ldots]$ que nos permite caminar paso a paso, detenernos cuando lo queremos" (Rojas 571). Y, por último, la conciencia del tiempo expropiado a la jornada laboral: "el 
que no tiene tiempo no tiene nada y de nada puede gozar el apurado, el que va de prisa, el urgido [...] No te apures, hombre, camina despacio y siente" (Rojas 571).

Considerando lo anterior, se entiende que la experiencia carcelaria no fue una situación poco habitual en el entorno de las clases populares. Transformar al vagabundo, al bandolero, al mendigo o al delincuente en un individuo útil para los ideales republicanos fue parte del proceso de regeneración que incluía el encierro. Era esta la "medicina" que los "curaría" al convertirlos en personas laboriosas y respetuosas de las instituciones. De hecho, fue ese el objetivo de la Ley de Alcoholes promulgada en 1902 que sancionaba la ebriedad pública y fortalecía las facultades de la policía para detener a quienes según su parecer se encontraban en dicho estado. Uno de sus artículos permitía el pago de una multa para evitar la cárcel, lo que funcionó como un estímulo para el aumento de las detenciones. Según los datos reunidos por un futuro médico en 1909, el año previo a la aplicación de esta medida solo el $13,1 \%$ de los detenidos ingresados a las comisarías de Valparaíso correspondía a personas en estado de ebriedad, porcentaje que en 1902 aumentó a 60,4\% y que en 1907 alcanzaba ya al 82,5\% (Zilleruelo 92). Los grupos y organizaciones que adscribieron a la matriz ilustrada del movimiento obrero fueron críticos a este tipo de detenciones, no por una defensa del consumo de alcohol, sino porque los apresados por este delito fueron en su gran mayoría trabajadores. En ese sentido, y expresiva de la matriz anarquista de su autor, en la novela se aprecia una crítica abierta a las cantinas que poblaban las calles y cerros porteños:

Con sus barandillas de madera, sus mesones, sus luces, sus decenas de mesas y sillas, [las cantinas] parecían no tener fin y se podía entrar y sentarse y estarse allí una noche entera bebiendo y al día siguiente y al subsiguiente y una semana y un mes y un año [...] Era fácil entrar; lo difícil era salir, excepto si se acababa el dinero o lo echaban a uno a la calle por demasiado borracho [...] Siempre, adentro o afuera, ocurrían riñas, sonaban gritos destemplados o estropajosos y se veían bocas desdentadas, ojos magullados y camisas destrozadas y con manchas de vino o de sangre (Rojas 471-472).

El alcohol, como elemento identitario y configurador de la sociabilidad masculina popular, atraviesa diversos pasajes y descripciones de personajes en Hijo de ladrón, como el borracho degradado en su condición humana con el cual Aniceto comparte su celda, o el maestro Jacinto, laborioso trabajador 
pero distante de la vida familiar producto de su exacerbado consumo: "Si no hubiese tanto vino en las cantinas, trabajaría menos", sentenciaba su mujer aludiendo a que el escaso salario se destinaba a ello: "Es lo único que le gusta -agregaba su esposa- [...] Lo más curioso de todo es que el vino no le hace nada; lo emborracha, es cierto, pero no lo enferma" (Rojas 565).

Por ello no sorprende que los socialistas de la década del diez hayan denunciado la estrecha unión de intereses entre los productores de alcohol, los cantineros, las autoridades municipales, los jueces y la policía, todos eslabones de la misma cadena de explotación capitalista. Aunque compartían la crítica de las clases dirigentes sobre el beber inmoderado, el objetivo de unos y otros era completamente diferente. Para los primeros, era un signo más de la decadencia moral y explicación del ausentismo laboral, para los trabajadores organizados, implicaba el alejamiento de la organización política (Navarro 2019). Considerando la cercanía de Manuel Rojas con grupos anarquistas, es posible advertir en sus reflexiones la matriz del obrerismo ilustrado que compartieron con los socialistas del período. En lo referente al consumo de alcohol, y para evitar este tipo de detenciones, ambas corrientes desarrollaron una serie de prácticas de entretención alternativas que tuvieron como público objetivo a las familias obreras, entre las que destacaron el teatro, los conciertos y las veladas literario-políticas, actividades relatadas con detención en las novelas siguientes que conforman la tetralogía.

La creciente asimilación de las clases populares con el delito (fuese por vagar, por embriaguez o por organizarse) produjo un desplazamiento de las funciones policiales desde el resguardo del bienestar general de la población, a acciones que reforzaban la protección de la propiedad privada mediante la represión, identificación y detención. En ese contexto, las técnicas de control y vigilancia se consolidaron como una especialidad policial que en un primer momento tuvo como foco al delincuente reincidente, para luego volcarse al registro general de los habitantes a partir de la obligatoriedad de la cédula de identidad (Palacios; León). La compulsión por el certificado, que tan amargamente es descrita al inicio de la novela, expresa la extensión de este mecanismo de administración social y política que inauguró una nueva relación entre el Estado y los ciudadanos ${ }^{15}$.

15 El 7 de octubre de 1924 se creó el Servicio de Identificación Personal, el que decretó la obligatoriedad de la libreta de identidad a los residentes nacionales y extranjeros que hubiesen cumplido dieciocho años. 
- Señor, necesito un certificado que acredite que soy argentino.

- ¡Ajá! ¿Y quién me acredita que lo es? ¿Tiene su certificado de nacimiento?

- No, señor

- [...] usted me trae sus papeles y yo le doy el certificado que necesita. Certificado por certificado. ¿Dónde nació usted?

(Bueno, yo nací en Buenos Aires, pero eso no tenía valor alguno; lo valioso era el certificado [...] ¡Tipos raros! A mí no me creían, pero le habrían creído al papel, que podía ser falso [...] Claro está que esto ocurría sólo con aquella gente) (Rojas 382).

Como se aprecia, la crítica apunta a la restricción de las libertades individuales concebida como condición de la seguridad nacional, además de un mecanismo de neutralización selectiva de aquellos individuos o grupos considerados "indeseados". Si para las autoridades lo central era el documento que acreditaba legal y moralmente la identidad pública y privada, para Aniceto estos gestos de racionalidad moderna eran el contrapunto de la condición humana y una más de las manifestaciones cotidianas de la coacción promovida por el liberalismo burgués:

El hombre parece no tener ya carácter humano, es un ente que posee o no un certificado y eso porque algunos individuos, aprovechando la bondad o la indiferencia de la mayoría, se han apoderado de la tierra, del mar, de los caminos, del viento y de las aguas y exigen certificados para usar de todo aquello [...] Están en todas partes y en donde menos se espera [...] y examinan los certificados, aceptándolos o no, guardándolos o devolviéndolos: no está en regla, le falta la firma, no tiene fecha; aquí debe llevar una estampilla de dos pesos [...] esa fotografía tanto puede ser suya como del arzobispo; esta firma no tiene rúbrica (Rojas 456-457).

Este tipo de reflexiones alerta también sobre las profundas consecuencias que tendría este mecanismo en su extensión al mundo del trabajo, específicamente en los modos de garantizar el orden y la reproducción capitalista en un contexto de agitación obrera. En 1906, la Municipalidad de Valparaíso facultó a la policía de seguridad a identificar fotográficamente a los cocheros, medida que al año siguiente se extendió a los suplementeros porteños, estos últimos asociados recurrentemente con la vagancia y la delincuencia (Cárdenas 108). La referencia de Rojas no es casual, pues hubo una resistencia colectiva frente a estas disposiciones en gremios más numerosos y con mayor tradición 
organizativa. Una de ellas fue la movilización que se conoció como "Huelga del Mono" en 1913, motivada por la obligación de retratar a los empleados a jornal de los Ferrocarriles del Estado y que se extendió a otros gremios gracias a la participación de anarquistas y socialistas (Godoy; Navarro 2017). A mediados de 1917, la obligatoriedad de la fotografía, esta vez destinada a los obreros portuarios de Valparaíso, fue el origen de una nueva huelga que no alcanzó a repercutir a nivel nacional como sí lo hizo la de 1913. A lo anterior debe sumarse la promulgación de la Ley de Residencia en 1918, situaciones que ilustran las consecuencias que tuvo la modernización de los métodos represivos ${ }^{16}$ y que la novela advierte a partir de la extensión obligatoria de los certificados. Consciente de la intención de criminalizar la protesta, el propio Rojas participa aquí del rechazo que los trabajadores expresaron a la identificación por considerarla tanto un dispositivo que los emparentaba con la delincuencia, como una herramienta de supervisión y control frente al avance del movimiento obrero ${ }^{17}$.

Bajo ese marco, tampoco sorprende que la experiencia carcelaria de las clases populares sea una de las dimensiones centrales que cruza su universo narrativo. El encierro podía vivirse como una experiencia de aprendizaje en el camino de hacerse hombre -el caso de Eugenio, personaje de Lanchas en la bahía-. O el lugar al que cualquier persona podía llegar sin por ello convertirse en un criminal -los relatos de los detenidos en los cuentos por ebriedad, riñas, juegos o malentendidos con la policía-. Y también como el epítome del disciplinamiento en el que convive la solidaridad y la fraternidad del ser humano, junto a la banalidad y el sinsentido -apreciaciones que

16 La Ley de Residencia de 1918 permitía la expulsión de los extranjeros considerados peligrosos y fue utilizada principalmente para reprimir a los militantes no chilenos del movimiento obrero radical (Plaza y Muñoz). Según Verónica Valdivia, con su promulgación se abre el proceso de "modernización" de la represión hacia las organizaciones de los trabajadores (partidos y sindicatos), es decir, el tránsito desde las matanzas masivas hacia la legalización de las prácticas represivas.

17 Como plantea Lila Caimari, la criminalización y penalización jurídica de las actividades anarquistas fue parte de un complejo proceso que asoció al activista libertario con el delincuente común. De acuerdo con la historiadora argentina, esta "asincronía del temor" tuvo como primera vía de asociación las tipologías delictivas descritas por el criminólogo Cesare Lombroso en su texto Los anarquistas de 1894, a lo que se sumaría, en los primeros años del siglo XX, la descripción del anarquismo como el primer grupo disidente a escala global, producto de la ola de atentados públicos y de violencia política acometida por individuos o grupos adscritos a esta corriente (La ciudad y el crimen 134-143). 
encontramos en Hijo de ladrón y en Sombras contra el muro-. A partir de esta identificación con el transgresor, el autor subvierte un orden representacional que vuelve a los personajes víctimas de la moralidad burguesa o perseguidos por su activismo, en un ejercicio declarado de desconfianza ante el poder que las instituciones modernas ejercieron sobre los ciudadanos. En este "descubrimiento del preso" que se desarrolló y profundizó en las primeras décadas del siglo XX (Caimari, Apenas un delincuente 238), la novela pone de manifiesto la cercanía con el depositario del castigo, así como la evidencia de que la cárcel era un lugar, otro más, al que llegaban las víctimas de las injusticias.

Si cualquier acto de resistencia podía transformar pequeñas conductas individuales en gestos solapados o abiertos de rebeldía, en esta mirada desde abajo era la propia comunidad la que ratificaba o no la condición de transgresión, en un proceso tensionado por el quiebre de tradiciones y por la ruptura de un orden social-moral. Para las clases dirigentes, la "masa" popular fue desestabilizadora, pues en ella se concentraban los rotos alzados que no respetaban dios ni ley. En contraste, los personajes de Rojas sancionaron actuares -como el del ratero o el del bebedor inmoderado-, pero esta condición no llegaba a convertirlos en despreciados. El orgullo y la dignidad de Cristián, aquel ladrón frustrado que intentó dedicarse al robo producto de la violencia que su vida familiar y el sistema le impuso, evidencian una cuota de admiración que traspasaba las decisiones individuales. A propósito de él, comenta el Filósofo:

Muchas veces he sospechado que en muchos individuos de esta tierra, sobre todo en los de las capas más bajas, sobrevive en forma violenta el carácter del antepasado indígena, no del indígena libre, sino del que perdió su libertad; es decir, conservan la actitud de aquél: silenciosos, huraños, reacios al trabajo, reacios a la sumisión; no quieren entregarse, y entregarse ¿para qué? Para ser esclavos. ¿Vale la pena? Hay gente que los odia por eso, porque no se entregan, porque no les sirven. Debo decirte que yo los admiro y los admiro porque no los necesito: no necesito que trabajen para mí, que me sirvan, que me obedezcan (Rojas 593-594).

Observada desde el mundo obrero, al cual el mismo Rojas perteneció, la sensación de fracaso de un orden social y de promesas incumplidas de igualdad trascendió la denuncia para transformarse en la base de una organización política clasista. Promoviendo la constitución de una clase capaz de autoeducarse y 
de luchar por la mejora de sus condiciones de vida materiales y subjetivas, anarquistas y socialistas contribuyeron activamente al cuestionamiento de la arquitectura estatal-policial impuesta a inicios del siglo XX. Aunque ambas matrices compartieron con las élites valores regenerativos, la experiencia carcelaria que muchos y muchas vivieron les permitió afirmar que el delito no era exclusivo de los pobres, sino un problema cuyo origen se explicaba por las condiciones de explotación. De ahí también el cuestionamiento al sistema carcelario como un espacio contrario a la rehabilitación y como dispositivo de degradación de la condición humana. Si unos concibieron el encierro como un instrumento de regeneración de las identidades populares, los otros disputaron y confrontaron esta visión otorgándole a la organización política dicho lugar. Pese a que la dimensión organizativa no aparece retratada tan claramente en Hijo de ladrón, sí fue la consciencia de esta estructura la que forjó la relación de Aniceto con las ideas libertarias y la que le permitió a Manuel Rojas pavimentar el camino que luego relató en Sombras contra el muro y La oscura vida radiante.

\section{CONCLUSIONES}

De qué manera la novela ilustra las estructuras de sentimiento compartidas por los pobres urbanos, qué imaginarios críticos sobre el moderno engranaje jurídico-moralizador es posible apreciar en este ejercicio narrativo, y cómo experimentaron las clases populares las medidas para enfrentar la delincuencia y las herramientas de control social fueron las interrogantes principales abordadas en el desarrollo del texto.

Como se vio en ambos apartados, el análisis histórico de Hijo de ladrón entrega luces sobre las contradicciones materiales y subjetivas que trajo el despertar del nuevo siglo, período marcado por la cuestión política y social, por las transformaciones derivadas del proceso de transición al capitalismo, por los avances en la organización obrera y por los cambios en la percepción de la delincuencia. En ese sentido, quise demostrar que en la narrativa de Rojas hay un distanciamiento respecto a la visión que construyeron las élites sobre las identidades populares, contraponiendo al discurso dominante una serie de prácticas espaciales y laborales que tensionaron el modelo impuesto.

Bajo ese marco, y a propósito del motín descrito en la novela, es posible indagar en ciertas "estructuras del sentir" popular, como la sensación de indefensión asociada a la pobreza, que convertía la igualdad ante la ley en un 
mero recurso retórico: "Soy un hombre de trabajo y no peleo con nadie; mucho menos se me ocurriría pelear con la policía, que siempre sale ganando", dice "El Azarcón" al juez tras ser detenido por participar de la revuelta (Rojas 505). O las asimetrías de poder que los volvían incapaces de revertir acusaciones falsas, dejando en evidencia las irregularidades, la parcialidad y los contenidos de clase sobre las que se sustentaba el sistema judicial: “¿Cómo convencer al juez de que no tuve nada que ver con aquel asalto a una joyería [...] que era un hombre honrado o que me tenía por tal?" (Rojas 505). Y también la criminalización de la protesta y la sanción a la legítima rabia derivada de la vivencia cotidiana de las desigualdades sociales: muchos hombres vieron en el motín la oportunidad para demostrar su antipatía "hacia los que durante meses y años explotan su pobreza y viven de ella" (Rojas 464).

Este conjunto de experiencias que da forma a las "estructuras de sentimiento" no debe entenderse sólo como resultado de la creatividad literaria de un individuo, sino más bien como expresión de las relaciones históricas entre los pobres y el Estado, forjada en sus encuentros y desencuentros con la policía y con el aparato judicial. La identidad que la élite construyó entre pobreza y delincuencia no fue abstracta; se verificaba cotidianamente en la ciudad, en los arrabales, en los conventillos, en el lugar de trabajo y en los momentos de protesta. Como sabemos, esta conflictiva relación es de largo aliento histórico y no deriva particularmente de la modernización estatal ni se reduce a ella. Lo novedoso de las primeras décadas del siglo XX fue la denuncia de sus implicancias y, en especial, la capacidad del movimiento obrero de organizarse y luchar por un proyecto clasista de transformación social. Como un producto de la década del cincuenta que enuncia una época anterior, Hijo de ladrón puede analizarse como parte de un discurso político que sostiene la defensa de la libertad humana, en diálogo con la sensibilidad de anarquistas y socialistas que cuestionaron los mecanismos punitivos dirigidos tanto a delincuentes como a trabajadores.

Las propuestas criminológicas positivistas, de amplio alcance entre los legisladores nacionales hasta por lo menos 1920, sirvieron para vincular la cuestión social y criminal. En su visión, los vagabundos y los trabajadores ocasionales fueron quienes tendieron a engrosar las filas de la "mala vida", de ahí que la experiencia carcelaria y los proyectos de reforma penitenciaria no puedan desligarse de los modos en que se buscó reproducir a la clase obrera.

El temor hacia los trabajadores organizados que desde fines del siglo XIX se incubó entre las clases dirigentes, se amplió en las décadas siguientes hacia otros segmentos del mundo popular, en particular hacia quienes se negaron a 
abrazar la disciplina y ética laboral. La ciudad, marco del proceso modernizador, fue el espacio donde la élite tuvo que convivir con las "clases peligrosas", en su mayoría pobres, desocupados y obreros. Pero también fue este el lugar donde la pobreza se articuló con nuevos imaginarios demandantes de igualdad y emancipación. Precisamente fue esta revolución en las expectativas la que los personajes de Rojas ilustran con sus experiencias de vidas al margen y cuestionamiento político.

\section{BIBLIOGRAFÍA}

Boletin de la Policía de Santiago. Santiago, 1901-1912.

Caimari, Lila. Apenas un delincuente. Crimen, castigo y cultura en la Argentina, 1880-1955. Buenos Aires: Siglo XXI Editores, 2012.

La ciudad y el crimen. Delito y vida cotidiana en Buenos Aires, 1880-1940. Buenos Aires: Sudamericana, 2009.

Cárdenas, Vania. El orden gañán. Historia social de la policia. Valparaíso, 1896-1920. Concepción: Ediciones Escaparate, 2013.

Galeano, Diego. Delincuentes viajeros. Estafadores, punguistas y policías en el Atlántico sudamericano. Buenos Aires: Siglo XXI Editores, 2018.

Godoy, Eduardo. La Huelga del Mono. Los anarquistas y las movilizaciones contra el retrato obligatorio (Valparaiso, 1913). Santiago: Quimantú, 2014.

León, Marco Antonio. Construyendo un sujeto criminal: criminología, criminalidad y sociedad en Chile: siglos XIX y XX. Santiago: Editorial Universitaria/DIBAM, 2015.

Navarro, Jorge. Revolucionarios y parlamentarios. La cultura politica del Partido Obrero Socialista, 1912-1922. Santiago: Lom Ediciones, 2017.

"Fiesta, alcohol y entretenimiento popular. Crítica y prácticas festivas del Partido Obrero Socialista. Chile, 1912-1922". Historia 52 (2019): 81-107.

Ossandón, Carlos y Eduardo Santa Cruz. El estallido de las formas. Chile en los albores de la "cultura de masas". Santiago: Lom Ediciones /Universidad Arcis, 2005.

Palacios, Cristián. "Policía de identificación. El bertillonage y la dactiloscopia en la Policía de Santiago de Chile, 1899-1924". Historia de la cuestión criminal en América Latina. Eds. Lila Caimari y Máximo Sosso. Rosario: Prohistoria Ediciones, 2017. 235-274.

Palma, Daniel. Ladrones. Historia social y cultura del robo en Chile, 1870-1920. Santiago: Lom Ediciones, 2011.

"El Boletín de la Policía de Santiago. Autorretrato de una policía urbana (19011924)". Policías escritores, delitos impresos. Coords. Diego Galeano y Marcos Luiz Breta. La Plata: Teseo, 2016. 109-133. 
Piccato, Pablo. "Rateros: lenguaje cotidiano, reforma social y crimen, 1890-1931". Instituciones y ciudad. Ocho estudios históricos sobre la Ciudad de México. Coords. Carlos Illades y Ariel Rodríguez. Ciudad de México: Colección Sábado, Distrito Federal, 2000. 217-246.

Plaza, Camilo y Víctor Muñoz C. "La Ley de Residencia de 1918 y la persecución a los extranjeros subversivos". Revista de Derechos Fundamentales 10 (2013): 107-136.

Rojas, Manuel. Hijo de ladrón. Obras escogidas, tomo I. Santiago: Zig-Zag, 1974.

Páginas excluidas. Santiago: Editorial Universitaria, 1997.

Romero, Luis Alberto. ¿Qué hacer con los pobres? Elites y sectores populares en Santiago de Chile, 1840-1895. Buenos Aires: Editorial Sudamericana, 1997.

Schopf, Federico. "Introducción”. Páginas excluidas. Manuel Rojas. Santiago: Editorial Universitaria, 1997. 13-38.

Sucesos. Valparaíso, 1908-1915.

Valdivia, Verónica. Subversión, coerción y consenso. Creando el Chile del siglo XX (19181938). Santiago: Lom Ediciones, 2017.

Williams, Raymond. Marxismo y literatura. Buenos Aires: Las Cuarenta, 2009.

Zaffaroni, Eugenio. "La 'mala vida' o los prejuicios vestidos de ciencia". Delito y sociedad 31 (2016): 23-36.

Zilleruelo, César. El alcoholismo en Chile y su relación con la criminalidad y la locura. Su represión. Santiago: Memoria de prueba, Facultad de Medicina y Farmacia Universidad de Chile, 1909. 